\title{
Applying Choice Architecture and Marketing Pre-Suasion to the Motorcycle Industry
}

\author{
Bethany Landis \\ University of West Florida \\ Stephen A. Lemay \\ University of West Florida \\ Dave McMahon \\ Pepperdine University
}

\begin{abstract}
In this analysis, we examine the motorcycle industry in terms of Cialdini's concept of Pre- Suasion. We use the chapter titles from the book to explore how these concepts could or should help the motorcycle industry adapt to shifts in its markets, shifts that are both demographic and cultural. In the process, we also explore ideas like product gentrification and choice architecture, ideas at the heart of the motorcycle marketing problem. We conclude that motorcycle promotions and messaging lack traction with younger buyers. We close with an extensive list of questions calling for further research.
\end{abstract}

Keywords: Cialdini, pre-suasion, motorcycle, gentrification, marketing

\section{INTRODUCTION}

The motorcycle industry has undergone a major cultural transition in the years since WWII. The transition has been a form of cultural appropriation and product gentrification based not on race but on perceived socio-economic class. In this paper, we argue that this change occurred, sometimes accidentally and sometimes deliberately, through mechanisms that we now recognize as parts of choice architecture. We begin by giving a brief description of the change in consumers of motorcycles since WWII and defining what we mean by choice architecture and gentrification. Then these changes are examined through the lens of Cialdini's work with a specific eye to how the motorcycle industry can attract the younger generations. We focus on three major processes: linking, weapons of influence, and post-suasion.

\section{A BRIEF HISTORY OF MOTORCYCLE CONSUMERS}

The images of the Hell's Angels-Easy Rider memes of the outlaw biker dominated the motorcycle of the imagination and of the identity for several decades after World War II. However, a survey of the 2019 attendees of the Sturgis Motorcycle Rally, an event that can draw upwards of 1,000,000 attendees (SDDOT, 2020) shows how much the consumer profile has changed. At the 2019 event, the average age of attendees 
was 54 (https://sturgismotorcyclerally.com/City-of-Sturgis-Holds-Post-Rally-Summit). Few of these over50 bikers would fit the Easy-Rider-Outlaw image that dominated movies at one time, although they may call on such images as part of their identities (Pugliese and Cagan, 2002). The new biker is often a middle manager or an accountant, over 50 years old, and lacking in training or experience on motorcycles. The industry's consumers overall are aging with only $32 \%$ in the 18-34 age group (IBISWorld, 2020).

The industry understands that it is in the maturity stage of the life cycle and is attempting to lure new customers into the fold, via multiple tactics, to revitalize the industry. Bundles are being offered to increase the perceived value of the offering while increasing the profits for the firm due to using low quality or low cost products in the bundling strategies (Lingzhi, 2019). Environmentally friendly motorcycles are being developed to appeal to those who have environmental concerns, and additional versions of existing products are being offered.

Much of the promotion is being done in traditional ways and aimed at a traditional audience, but firms are also trying to attract the younger generations and women. This messaging creates conflicts with the promotions to the new markets, resulting in messaging that can be viewed as confusing and inconsistent. In addition, this messaging is not adapting as well as it could to the way the new generations interact with the messaging. Motorcycle firms are attempting to create products for the younger generation and enter this market segment. Unfortunately, they are currently failing. For example, companies like Harley-Davidson are attempting to create smaller, less powerful, less expensive motorcycles, but the product strategy has yet to grab the attention of the targeted younger generation. They may recognize brands and favor them in video games, but they are not buying them in real life (Gupta, 2016). These conflicts highlight the need to explore how linking, weapons of influence, and post-suasion can be applied to and make a difference in this industry.

\section{CHOICE ARCHITECTURE AND GENTRIFICATION}

Choice architecture developed in the context of behavioral economics and social psychology (Kahneman and Tversky 1982; Sunstein and Thaler 2003), and, perhaps most prominently, in marketing (Cialdini and Goldstein, 2004). Choice architecture refers to the idea that changes in decision context can influence decision making and behavior while retaining a full range of options (Münscher, Vetter, \& Scheuerle, 2016). Gentrification is usually "defined as the transformation of inner city working class and other neighborhoods to middle and upper-middle class residential, recreational, and other uses" (Smith, 1987). However, the term has more recently been associated with cultural or class appropriation (Hanlon and Cohen, 2006; Schouten, Martin, and McAlexander, 2012; Schouten and McAlexander, 1995). Schouten and others have executed several ethnographic studies that show how the motorcycle culture of consumption has changed since the "Easy Rider" image of the past (Schouten, Martin, and McAlexander, 2012; Schouten and McAlexander, 1995). Others have chosen to describe this idea as a process of product gentrification (Hanlon and Cohen, 2006).

\section{The Primary Associations: I Link, Therefore I Think}

Cialdini cites correlations between words or images and the reaction or actions that follow. Exposure to simple words or images can later have persuasion, that is, influence before the persuasive message delivers influence on future decisions, only because of the experience the mind has with a certain word or image. Language should no longer be thought of as a way to convey information, but rather as a way to influence behavior.

Within the context of the motorcycle industry, the goal should not be to explain the position motorcycles provide, but instead to persuade the consumer to make the purchase. In some situations, the motorcycle industry can remove itself from thinking that it needs to list off the product features. Instead, motorcycle companies can strive to change the language used around its products to persuade the customer as to why he or she needs to own a motorcycle. Motorcycle companies can focus on the "feeling" and "power" of owning a motorcycle and the status or lifestyle that comes with the ownership. With Gen Y, this idea is particularly effective as they spend their money on experiences. In a recent survey by EventBrite (2014), 
$78 \%$ of Millennials indicated they would rather buy an experience than a product. Describing the experience of owning a motorcycle may be far more effective than listing its features or framing it as a material possession. Motorcycle companies have a unique opportunity to own the middle ground that combines experiences with possessions thus allowing the experience to occur on demand.

In the motorcycle industry, companies could use this power of association by putting happy, successful young people on advertisements riding motorcycles to help gain more market share in the younger generation. Words that hold a lot of influence with millennials could be used on promotional pieces to help persuade the young purchaser to buy a motorcycle. For instance, in 2020, the word "vintage" has a lot of power behind it with the younger generation (Hansson, 2020). That word could be used on advertisements to influence the mind of potential riders to connect owning a motorcycle with experiencing a vintage lifestyle.

\section{Weapons of Influence}

In his chapter, Six Main Roads to Change: Broad Boulevards as Smart Shortcuts, the author speaks to his six main concepts around influence: reciprocation, liking, social proof, authority, scarcity, and consistency. Two of these concepts, liking and consistency, are very applicable and relevant to the motorcycle industry. Liking is comprised of similarities and compliments. The author explains how we like those who are like us.

With the motorcycle industry in the mature stage of its life cycle, companies within the industry are attempting to bring in younger riders to create a higher degree of liking. Companies can hire individuals from the younger generation to work at dealerships so if younger customers come in, both individuals are more likely to relate to one another and like each other. Marketing promotions can have younger riders involved so that consumers feel a connection. Motorcycle companies can strive to find ways to compliment consumers so that the customers feel liked and trust the companies. (Lechner and Paul, 2019; Ying-Lee, Liu, \& Luk, 2017)

Additionally, consistency is a strong concept needing an extra boost in the motorcycle industry. Companies are continuing to promise smaller, less powerful motorcycles that are affordable to the younger generation, but then the product that is released is still thousands of dollars more than what the target market can afford. For instance, Harley-Davidson released its LiveWire electric motorcycle that was meant to target the young, environmentally friendly group of consumers in an affordable way; yet, the price tag ended up being far too high--\$29,799 for the 2020 model (Harley-Davidson.com, 2020). This price might appeal to environmentally conscious riders in the traditional age groups, but it puts the price beyond the reach of younger consumers. Motorcycle companies want and need to be consistent, as this practice is emphasized by Cialdini. This will enable consumers to recognize the commitment being made by the company and be able to act upon the offer being presented. Consistency and commitment help to build loyalty which results in future purchases, although these concepts have not been studied in the context of motorcycle sales (Šerić, Ozretić-Došen, \& Škare. (2020). Consistency means congruence of messages through all channels, including advertising, social media, and in-store personnel.

\section{Post-Suasion: Aftereffects}

When making a change, pre-suaders want the change to be more than temporary and to take root. The author highlights that one way to make a change lasting is to instill strong commitments. By providing an active step to take to stay true to a commitment, the change is more likely to occur and remain. Active steps can be taken during each stage of the adoption process to improve the movement of potential purchasers through the process. For instance, motorcycle companies in the industry could create environments for their customers to become committed. This will need to be implemented across all stages of the adoption process.

At the awareness stage, firms need to be prepared for this initial interaction taking place either in the store, online, or both. In a combinatory situation, it is critical for the firm to pay particular attention to the in-store interaction as these interactions drive consumer online value perceptions (Verhagen, Dolen, and Merikvie, 2019). The initial call to action for the consumer could be as simple as asking customers to leave their email address or contact information if they are interested in a motorcycle. 
At the interest stage, the companies could stage events for those who shared their information, where the interested customers ask more questions and evaluate their motorcycle. The trial stage could be a riding event on a closed course much like Mercedes does for well qualified potential customers. Adoption can be secured before the customer takes ownership by following the example of Tesla when a new product is being released. They ask customers to submit a payment to guarantee they get the product. In this case, the commitment is more likely to stick since an action item was provided and the customer is now invested.

\section{CONCLUSIONS}

From this initial view, traditional motorcycle brands lack traction among younger buyers. This comes partly from sluggishness in abandoning traditional marketing messages because the older riders still generate most of the revenue, but also because manufacturing pricing strategies remain the same as well. The motorcycle industry has adapted poorly to the sea change of consumers in the last twenty years, so younger consumers still feel left out or betrayed by inconsistent messaging.

This also suggests that the major brands have difficulty sending more than one message at a time. They still appeal to the fading Easy Rider identity of the older consumer, but have not yet adapted a consistent, trustworthy message for the younger, often more pragmatic consumer. Further, it suggests that much remains to be learned about this market and its future, especially in the developed economies where motorcycles are either luxury items or transportation options that are almost as costly as cars.

\section{FUTURE RESEARCH}

As companies are fighting to stay profitable, several interesting topics should be explored. First, do motorcycle firms understand the cost of multiple SKUs and their impact on the bottom line? How are they addressing this? Some companies have streamlined their choices to the point of only offering one model but is this a win-win scenario? As the industry tries to attract and cultivate a new generation of motorcycle enthusiasts, how important are choices for the first time motorcycle purchaser? Other companies are maintaining their product line but making use of bundles to increase the value proposition. Research needs to determine if these bundles are effective in driving sales and, if so, which bundles work best for which market segments? Is the younger, experience focused buyer more interested in an experience package than a bundle of additional products? If yes, what should that bundle look like to drive adoption among the younger buyers? In further exploring the multi-channel approach to attracting these new customers, studies should be conducted on how congruent is the information and experience of potential motorcycle purchasers across channels. As part of this multichannel approach, research should determine which influencers are most likely to influence the purchase of a motorcycle by a millennial. Lastly, in the controversial times we live in, how will a company weighing in on a controversial issue, perhaps whether to wear a helmet, impact the effect of different segments toward the company and what is the impact of that on sales? Obviously, this analysis raises more questions than it answers. Much more research is needed, not just in the motorcycle industry, but in most industries.

\section{SUMMARY}

The motorcycle industry is searching for ways to grow and innovate, but the industry is encountering not only consumer lifecycle changes, but also the changing market culture of the industry. Product gentrification is occurring as motorcycle products transition from typical working class products to products used by the middle and upper classes for both residential and recreational uses. When these changes are examined through the lens of Cialdini's work, with a specific eye to how the motorcycle industry can attract the younger generations, we find possible solutions based upon the three major processes of linking, weapons of influence, and post- suasion. 


\section{REFERENCES}

Baba, M. (2015). Cost reduction analysis in the online retail as compared to classic retail. Economic Sciences, 8(1), 141-146.

Bachynski, K. (2012, December). Playing hockey, riding motorcycles, and the ethics of protection. American Journal of Public Health, 102(12), 2214-2220.

Cialdini, R. (2016). Pre-Suasion: A revolutionary way to influence and persuade. Simon \& Schuster Paperbacks. New York: Simon \& Schuster.

Cialdini, R.B., \& Goldstein, N.J. (2004). Social influence: Compliance and conformity. Annual Review of Psychology, 55, 591-621.

Droege, S. (2009). Indian Motorcycle Company: Strategy for market reentry. Journal of the International Academy for Case Studies, 15(1), 55-64.

Dorocki, S. (2018). Changes in the market of two and three-wheeled motor vehicles in Europe at the beginning of the 21st century. Entrepreneurial Business and Economics Review, 6(1) 175-193.

EventBrite. (2014). Retrieved from http://eventbrites3.s3.amazonaws.com/marketing/Millennials_Research/Gen_PR_Final.pdf

Gupta, G., \& Singla, V. (2016, December). A study on selection of most preferred brands. IUP Journal of Brand Management, 13(4), 24-35.

Halnon, K.B., \& Cohen, S. (2006). Muscles, motorcycles and tattoos: Gentrification in a new frontier. Journal of Consumer Culture, 6(1), 33-56.

Hansson, C.F. (2020). Enlightening the Present with the Past-Consumer's Yearning for a Past Ethos: The Meaning Construction of Vintage Objects.

Kahneman, D., \& Tversky, A. (1982). The psychology of preferences. Scientific American, 246(1), 160173.

Lechner, A.T., \& Paul, M. (2019). Is this smile for real? The role of affect and thinking style in customer perceptions of frontline employee emotion authenticity. Journal of Business Research, 94, 195208.

Ling-Yee Li, E., Liu, B.S.C., \& Luk, S.T. (2017). Customer participation behavior in high-versus lowcontact services: The multiple roles of customer trust. Journal of Global Marketing, 30(5), 322341.

Lingzhi, S. (2019, January). Bundling and product strategy in channel competition. International Transactions in Operational Research, 26(1), 248-269.

Münscher, R., Vetter, M., \& Scheuerle, T. (2016). A review and taxonomy of choice architecture techniques. Journal of Behavioral Decision Making, 29(5), 511-524.

Pugliese, M.J., \& Cagan, J. (2002). Capturing a rebel: Modeling the Harley-Davidson brand through a motorcycle shape grammar. Research in Engineering Design, 13(3), 139-156.

Schouten, J.W., Martin, D.M., \& McAlexander, J.H. (2012). The evolution of a subculture of consumption. In Consumer Tribes (pp. 82-90). Routledge.

Schouten, J.W., \& McAlexander, J.H. (1995). Subcultures of consumption: An ethnography of the new bikers. Journal of Consumer Research, 22(1), 43-61.

Šerić, M., Ozretić-Došen, Đ., \& Škare, V. (2020). How can perceived consistency in marketing communications influence customer-brand relationship outcomes? European Management Journal, 38(2), 335-343.

Smith, N. (1987, September). Gentrification and the rent gap. Annals of the Association of American Geographers, 77(3), 462-465.

Thaler, R.H., \& Sunstein, C.R. (2003). Libertarian paternalism. American Economic Review, 93(2), 175179.

Verhagen, T., Dolen, W., \& Merikivi, J. (2019, March). The influence of in-store personnel on online store value: An analogical transfer perspective. Psychology and Marketing, 36(3), 161-174. 